\title{
The impact of political risk on return, volatility and discontinuity: Evidence from the international stock and foreign exchange
}

\author{
markets
}

\author{
Dimitrios I. Vortelinos*and Shrabani Saha ${ }^{\dagger}$
}

March 11, 2016

\begin{abstract}
The paper examines the impact of political risk on stock and foreign exchange markets in a comprehensive sample of sixty-six countries and twenty political risk indicators mostly covering the financial crisis and recovery periods from May 2001 to April 2014. The impact is assessed on return, volatility and jumps series of monthly frequency. Evidence reveals that Europe is mostly at higher risks generated from economic crisis; whereas, political risks explain the high volatility and discontinuity in international stock and foreign exchange markets in other regions.
\end{abstract}

Keywords: Political risk; Volatility; Jumps.

JEL Classification Codes: G15; G18; F38.

${ }^{*}$ Corresponding author. Lincoln Business School, University of Lincoln, UK. Contact at dvortelinos@lincoln.ac.uk, 00441522-835634 (tel.).

†Lincoln Business School, University of Lincoln, UK. Contact at ssaha@lincoln.ac.uk, 0044-1522-835547 (tel.). 


\section{Introduction}

The existing literature examines the political risk impact on macroeconomic fundamentals (Bekaert et al., 2013) and government bond yields (Huang et al., 2015), and few country-specific studies have investigated the influence of political risk on the stock and foreign exchange markets (Bailey and Chung, 1995; Perotti and van Oijen, 2001). However, there is no cross-country study that captures the impact of political risk on volatility and jumps of stock and foreign exchange markets during the global financial crisis and the recovery periods. Volatility and jumps measure the market risk and discontinuities considered to be the most crucial factors for risk management, trading and asset allocation. This study fills the gap in the literature by focusing on the impact of political risk indicators on returns, volatility and jumps in stock and foreign exchange markets. The political risk indicators are assessed both regionally and internationally for the period 2001 to 2014 . Interestingly, the analysis explores both economic and political risks.

Contrarily to Huang et al. (2015) which focus on the effect of political crises to government bond yields, the present paper contributes by capturing the direct impact of political risk on the returns, volatility and jumps in stock and foreign exchange markets. The entire analysis is implemented in a monthly frequency. Volatility is estimated by using the median realized variance estimator (Andersen, Dobrev and Schaumburg, 2012) and jumps are detected and estimated following Duong and Swanson (2015). Twenty political risk indicators covering four groups of political risk (government stability, socioeconomic conditions, investment profile and internal conflict) and a composite index are assessed.

\section{Methodology}

Monthly realized volatility is estimated by the median realized variance $\left(M R V_{t}\right)$ which is considered as the best alternative jump-robust estimators of realized variance introduced by Andersen, Dobrev and Schaumburg (2012). The $\left(M R V_{t}\right)$ is defined as:

$$
M R V_{t}=\frac{\pi}{6-4 \sqrt{3}+\pi} \cdot \frac{N}{N-2} \cdot \sum_{l=2}^{N-1} \operatorname{med}\left(\left|R_{t, l-1}\right|,\left|R_{t, l}\right|,\left|R_{t, l+1}\right|\right)
$$

where $R_{t, l}$ is the daily return for $l$ day within month $t$ and $l=1, . ., N$ is the total number of daily observations within a month.

Jumps are detected in accordance to a non-jump volatility measure. Corsi et al. (2010) showed that the threshold bipower variation estimator is substantially better than others for such purposes. The threshold bipower variation $\left(T B P V_{t}\right)$ is given by: 


$$
T B P V_{t}=\sum_{i=2}^{22}\left|R_{t, i-1}\right| \cdot\left|R_{t, i}\right| \cdot I_{\left|R_{t, i-1}\right|^{2} \leq \vartheta_{i-1}} \cdot I_{\left|R_{t, i}\right|^{2} \leq \vartheta_{i}}
$$

where $I_{\{\cdot\}}$ is the indicator function and the threshold function, $R_{t, i}$ is the daily return series and $t$ is time in months. Barndorff-Nielsen and Shephard (2006) developed the jumps detection scheme based on bipower variation; and recently, Bekaert and Hoerova (2014) used the $T B P V_{t}$ dependent jumps detection scheme successfully. Another recent study on jumps from realized volatility is Duong and Swanson (2015). The jumps statistic is:

$$
Z J_{t}^{(T B P V)}=\sqrt{22} \cdot \frac{\left(R V_{t}-T B P V_{t}\right) R V_{t}^{-1}}{\left(\left(\xi_{1}^{-4}+2 \xi_{1}^{-2}-5\right) \max \left\{1, T Q_{t} T B P V_{t}^{-2}\right\}\right)^{1 / 2}}
$$

where $R V_{t}$ is the medial realized volatility $\left(M R V_{t}\right)^{1}$, and $T Q_{t}$ is the realized tripower quarticity which is $T Q_{t}=22 \cdot \xi_{4 / 3}^{-3} \cdot \sum_{i=1}^{22}\left|R_{t, i}\right|^{4 / 3}\left|R_{t, i+1}\right|^{4 / 3}\left|R_{t, i+2}\right|^{4 / 3}$ and converges in probability to integrated quarticity. The $Z J_{t}^{(T B P V)}$ statistic follows standard normal distribution. A jump is considered to be significant if the test statistic exceeds the appropriate critical value of the standard normal distribution, denoted by $\Phi_{\alpha}$, at $\alpha$ level of significance. A $95 \%$ significance level is employed. ${ }^{2}$ The jump component is:

$$
J_{t}^{(T B P V)}=\left[R V_{t}-T B P V_{t}\right] \times I\left[Z J_{t}^{(T B P V)}>\Phi_{a}\right]
$$

where $I[\cdot]$ is the indicator function of the $Z J_{t}^{(T B P V)}$ statistic in excess of a given critical value of the Gaussian distribution $\Phi_{a}$. The summation of the squared jump component and the continuous component of the $R V_{t}$ estimator equals to $R V_{t}$.

The direct effect of political risk is assessed with the use of control variables, as suggested in Huang et al. (2015) and Gennaioli et al. (2014). Following Huang et al. (2015), the ordinary least squares method employed is:

$$
X_{i, t}=a_{0}+a_{1} \operatorname{Pol}_{i, t}+a_{2} I N F L_{i, t}+a_{3} M C_{i, t}+a_{4} G D P_{i, t}+a_{5} I T_{i, t}+a_{6} I N T_{i, t}+e_{i, t}
$$

where $X_{i, t}$ is either return, volatility or jumps series of a country $i$ in time $t$ (in months); $P$ ol $l_{i, t}$ is any one from the twenty political indicator as split into five categories. Control variables are: inflation rate $\left(I N F L_{i, t}\right)$, stock market capitalization $\left(M C_{i, t}\right)$, Gross Domestic Product $\left(G D P_{i, t}\right)$, trade integration $\left(I T_{i, t}\right)$ and interest rate $\left(I N T_{i, t}\right)$. Newey-West robust standard errors are employed across all empirical analyses.

\footnotetext{
${ }^{1}$ The $R V_{t}$ is employed in the jumps detection scheme in order to comply with the literature.

${ }^{2}$ There are not significant changes in intensity and magnitude of volatility jumps for a $99 \%$ significance level.
} 


\section{Data}

Dataset begins on May 1, 2001 and ends on March 31, 2014, for a total of 3,410 trading days. All stock and foreign exchange daily data are in US dollars and obtained from Datastream. ${ }^{3}$ Sixty-six countries (split in four regions/continents) are considered. ${ }^{4}$ The countries selected in this study are with the most significant economies and stock markets in their regions/continents. The most widely used International Country Risk Guide (ICRG) monthly political risk indicators are obtained from the Political Risk Services. Their values range from 0 to 12; where 0 means the highest political risk. The control variables of inflation rate, stock market capitalization, GDP (Gross Domestic Product), trade integration and interest rate are retrieved from the Economic Outlook Database of the International Monetary Fund in October 2014 in quarterly and monthly frequency. ${ }^{5}$ Trade integration is measured as the ratio of international trade (imports plus exports) over the country's GDP.

\section{Empirical results}

The descriptive statistics of the continuous returns, volatility and jumps (average, maximum and minimum) of the international stock and foreign exchange markets are presented in Tables $1 \mathrm{~A}$ and $1 \mathrm{~B}$, respectively. The results suggest that stock markets in Europe are high in risk as the region displays the highest average return, volatility and jumps. Moreover, the maximum return, risk and discontinuity appear to be the highest compared to other regions. On the other hand, the North American region shows the highest average returns (with higher standard deviation) and volatility in the foreign exchange market (Table 1B). This may explain the fact that both global financial crisis and its recovery have started from the USA. However, Europe has the highest maximum average return, risk and discontinuity in the foreign exchange market compared to other regions indicating a greater exposure of vulnerability in both markets.

[TABLES 1A and 1B ABOUT HERE]

The results of the average political risk indicators (Table 2) suggest that North American region is less risky and provides better government stability, socioeconomic conditions and investment profiles, compared to the other regions.

[TABLE 2 ABOUT HERE]

Table 3 reports the impact of political risk on the international stock and foreign exchange markets. Most of the political risk indicators have a statistically significant impact on international stock and foreign

\footnotetext{
${ }^{3}$ For the purpose of the study, stock and foreign exchange daily data are converted into monthly frequency.

${ }^{4}$ The names of countries and their respective stock indices and exchange rates are available upon request from authors.

${ }^{5}$ For quarterly data, a linear interpolation based on the monthly ones, is implemented.
} 
exchange markets. ${ }^{6}$ The results show that with few exceptions, less political risk decreases the returns, volatility and jumps in both the markets in North America. In contrast, less political risk increases the returns, volatility and jumps both in terms of average and maximum in Europe in both the markets reflecting that less political risk is unable to control the volatility and jumps in Europe due to the more volatile economic risks. However, a greater political risk imposes higher risk and volatility in both the markets in Greece. ${ }^{7}$ Also, greater political risks increase the returns in the African and Asian regions. Results are robust to different sub-samples based on various international economic crises with an international impact. 8 The signs of the coefficients of the control variables are according to our expectations and consistent with Huang et al. (2015). ${ }^{9}$

[TABLE 3 ABOUT HERE]

\section{Conclusions}

The paper empirically analyses the impact of political risk on the stock and foreign exchange markets by measuring the returns, volatility and jumps for the sixty-six countries mostly covering the global financial crisis and the recovery periods. The results show that Europe and Americas are at greater risk, in terms of volatility and discontinuity in stock and foreign exchange markets compared to the other regions. On the other hand, political risks have greater influence in the other regions than Europe. Alternatively, Europe shows greater risk evolving from the economic crisis than political. Also, the country-specific macroeconomic fundamentals significantly explain return, volatility and jumps series.

Policy makers should incorporate the political risk factors while considering the market participations. Financial institutions and institutional investors invest most of their portfolios in stock and/or foreign exchange markets, the significant impact of political risk requires that the diversification benefit should be considered. In particular, the North American region should be considered as the region whose financial markets are mostly affected by political risk; whereas, Europe is the region whose financial markets are embedded with systemic risk in returns, volatility and jumps due to the economic risk. These results are in line with the ongoing European debt crisis.

\footnotetext{
${ }^{6}$ The minimum values in Table 3 suggest that higher political risks (lower value of political risk indicators) increase the return, volatility and jumps in both the markets in all the regions.

${ }^{7}$ Greece represents the minimum values for Europe in Table 3.

${ }^{8}$ These are: Argentine crisis (1/12/2001 up to $\left.29 / 11 / 2002\right)$, Global financial crisis $(18 / 7 / 2007$ up to $27 / 8 / 2009)$ and EU debt crisis $(8 / 12 / 2010$ up to $31 / 12 / 2011)$; as suggested by Cho et al. (2015). Results are available upon request.

${ }^{9}$ Results are available upon request.
} 


\section{References}

[1] Andersen, T.G., Dobrev, D., Schaumburg, E., 2012. Jump-robust volatility estimation using nearest neighbor. J. Econometrics 169 (1), 75-93.

[2] Bailey, W., Chung, P.Y., 1995. Exchange rate fluctuations, political risk, and stock returns: Some evidence from an emerging market. J. Fin. Quant. Anal. 30 (4), 541-561.

[3] Barndorff-Nielsen, O.E., Shephard, N., 2006. Econometrics of testing for jumps in financial economics using bipower variation. J. Financ. Econometrics 4 (1), 1-30.

[4] Bekaert, G., Hoerova, M., 2014. The VIX, the variance premium and stock market volatility. J. Econometrics 183 (2), 181-192.

[5] Bekaert, G., Hoerova, M., Lo Duca, M., 2013. Risk, uncertainty and monetary policy. J. Monetary Econ. 60 (7), 771-788.

[6] Cho, S., Hyde, S., Nguyen, N., 2015. Time-varying regional and global integration and contagion: Evidence from style portfolios. Int. Rev. Financ. Anal. 42, 109-131.

[7] Corsi, F., Pirino, D., Reno, R., 2010. Threshold bipower variation and the impact of jumps on volatility forecasting. J. Econometrics 159 (2), 276-288.

[8] Duong, D., Swanson, N.R., 2015. Empirical evidence on the importance of aggregation, asymmetry, and jumps for volatility prediction. J. Econometrics 187 (2), 606-621.

[9] Gennaioli, N., Martin, A., Rossi, S., 2014. Sovereign default, domestic banks, and financial institutions. J. Finance 69 (2), 819-866.

[10] Huang, T., Wu, F., Yu, J., Zhang, B. 2015. International political risk and government bond pricing. J. Bank. Finance 55, 393-405.

[11] Perotti, E.C., van Oijen, P., 2001. Privatization, political risk and stock market development in emerging economies. J. Int. Money Finance 20 (1), 43-69. 


\section{Tables}

\begin{tabular}{|c|c|c|c|c|c|}
\hline \multicolumn{6}{|c|}{ Table 1A. International stock markets } \\
\hline & \multicolumn{2}{|c|}{ Returns } & \multirow{2}{*}{$\begin{array}{l}\text { Volatility } \\
\text { Average }\end{array}$} & \multicolumn{2}{|c|}{ Jumps } \\
\hline & Average & St. deviation & & Average & St. deviation \\
\hline & \multicolumn{5}{|c|}{ Panel A. Average } \\
\hline AFRICA & 0.041 & 0.606 & 0.131 & 0.022 & 0.019 \\
\hline AMERICAS & 0.045 & 0.396 & 0.107 & 0.025 & 0.021 \\
\hline ASIA & 0.086 & 0.052 & 0.184 & 0.035 & 0.036 \\
\hline \multirow[t]{2}{*}{ EUROPE } & 0.108 & 0.753 & 0.187 & 0.044 & 0.027 \\
\hline & \multicolumn{5}{|c|}{ Panel B. Maximum } \\
\hline AFRICA & 0.167 & 1.08 & 0.265 & 0.032 & 0.027 \\
\hline AMERICAS & 0.133 & 0.765 & 0.246 & 0.091 & 0.054 \\
\hline ASIA & 0.083 & 0.774 & 1.01 & 0.099 & 0.092 \\
\hline \multirow[t]{2}{*}{ EUROPE } & 0.193 & 3.93 & 1.12 & 0.529 & 0.291 \\
\hline & \multicolumn{5}{|c|}{ Panel C. Minimum } \\
\hline AFRICA & 0.045 & 0.275 & 0.034 & $7.51 \mathrm{e}-3$ & 0.060 \\
\hline AMERICAS & $7.78 \mathrm{e}-3$ & 0.139 & 0.037 & $2.95 \mathrm{e}-4$ & 0.071 \\
\hline ASIA & $3.79 \mathrm{e}-3$ & 0.078 & 0.018 & $7.33 \mathrm{e}-4$ & 0.063 \\
\hline EUROPE & $7.79 \mathrm{e}-3$ & 0.176 & 0.029 & $2.73 \mathrm{e}-4$ & 0.037 \\
\hline
\end{tabular}




\begin{tabular}{|c|c|c|c|c|c|}
\hline \multicolumn{6}{|c|}{ Table 1B. Foreign exchange markets } \\
\hline & \multicolumn{2}{|c|}{ Returns } & \multirow{2}{*}{$\begin{array}{l}\text { Volatility } \\
\text { Average }\end{array}$} & \multicolumn{2}{|c|}{ Jumps } \\
\hline & Average & St. deviation & & Average & St. deviation \\
\hline & \multicolumn{5}{|c|}{ Panel A. Average } \\
\hline AFRICA & 0.070 & 0.220 & 0.081 & 0.025 & 0.018 \\
\hline AMERICAS & 0.074 & 0.573 & 1.04 & 0.417 & 0.191 \\
\hline ASIA & 0.028 & 0.194 & 0.227 & 0.032 & 0.021 \\
\hline \multirow[t]{2}{*}{ EUROPE } & 0.034 & 0.315 & 0.880 & 0.662 & 0.496 \\
\hline & \multicolumn{5}{|c|}{ Panel B. Maximum } \\
\hline AFRICA & 0.143 & 0.286 & 0.103 & 0.033 & 0.037 \\
\hline AMERICAS & 0.191 & 1.77 & 7.54 & 3.52 & 1.36 \\
\hline ASIA & 0.265 & 0.684 & 2.21 & 0.322 & 0.140 \\
\hline \multirow[t]{2}{*}{ EUROPE } & 0.393 & 2.60 & 11.25 & 10.22 & 7.08 \\
\hline & \multicolumn{5}{|c|}{ Panel C. Minimum } \\
\hline AFRICA & $3.06 \mathrm{e}-3$ & 0.162 & 0.059 & 0.021 & $7.98 \mathrm{e}-3$ \\
\hline AMERICAS & $9.70 \mathrm{e}-4$ & 0.102 & $1.85 \mathrm{e}-3$ & $7.38 \mathrm{e}-5$ & $1.14 \mathrm{e}-3$ \\
\hline ASIA & $2.13 \mathrm{e}-10$ & $6.53 \mathrm{e}-8$ & $1.37 \mathrm{e}-4$ & $3.55 \mathrm{e}-6$ & $2.49 \mathrm{e}-3$ \\
\hline EUROPE & $5.22 \mathrm{e}-4$ & 0.013 & 0.013 & $8.85 \mathrm{e}-7$ & $2.49 \mathrm{e}-5$ \\
\hline
\end{tabular}




\begin{tabular}{|c|c|c|c|c|}
\hline \multicolumn{5}{|c|}{ Table 2. Political risk indicators } \\
\hline \multirow[b]{3}{*}{ AFRICA } & GS & $\mathrm{SC}$ & IP & $\mathrm{IC}$ \\
\hline & \multicolumn{4}{|c|}{ Panel A. Average } \\
\hline & 1.65 & 3.58 & 4.89 & 5.85 \\
\hline AMERICAS & 2.13 & 4.60 & 6.50 & 5.71 \\
\hline ASIA & 1.44 & 3.93 & 6.26 & 4.03 \\
\hline \multirow[t]{2}{*}{ EUROPE } & 1.75 & 3.62 & 5.99 & 7.34 \\
\hline & \multicolumn{4}{|c|}{ Panel B. Maximum } \\
\hline AFRICA & 2.15 & 5.46 & 5.82 & 6.23 \\
\hline AMERICAS & 11.65 & 11.48 & 9.72 & 9.70 \\
\hline ASIA & 7.11 & 9.40 & 11.79 & 11.08 \\
\hline \multirow[t]{2}{*}{ EUROPE } & 7.12 & 9.36 & 11.97 & 11.99 \\
\hline & \multicolumn{4}{|c|}{ Panel C. Minimum } \\
\hline AFRICA & 1.18 & 2.51 & 2.18 & 1.67 \\
\hline AMERICAS & 1.03 & 0.988 & 0.674 & 1.37 \\
\hline ASIA & 1.05 & 1.00 & 1.35 & 1.59 \\
\hline EUROPE & 1.13 & 1.54 & 1.82 & 2.12 \\
\hline
\end{tabular}

Notes. The groups of indicators are: government stability (GS), socioeconomic conditions (SC), investment profile (IP) and internal conflict (IC). The higher value indicates less political risk. 


\begin{tabular}{|c|c|c|c|c|c|c|}
\hline \multirow[b]{4}{*}{ AFRICA } & \multicolumn{3}{|c|}{ Stock markets } & \multicolumn{3}{|c|}{ Foreign exchange markets } \\
\hline & Return & Volatility & Jumps & Return & Volatility & Jumps \\
\hline & \multicolumn{6}{|c|}{ Panel A. Average } \\
\hline & -0.325 & 0.313 & 1.62 & -0.178 & 0.692 & 0.983 \\
\hline AMERICAS & 0.220 & -0.058 & -0.478 & -0.012 & $-6.40 \mathrm{e}-3$ & 0.722 \\
\hline ASIA & -0.041 & 0.120 & 0.727 & -0.011 & -0.260 & 0.329 \\
\hline \multirow[t]{2}{*}{ EUROPE } & 0.141 & 0.125 & 0.919 & 0.050 & 0.063 & 0.284 \\
\hline & \multicolumn{6}{|c|}{ Panel B. Maximum } \\
\hline AFRICA & 0.625 & 0.768 & 4.32 & 0.083 & 0.231 & 2.85 \\
\hline AMERICAS & 1.79 & 1.61 & 4.73 & 1.12 & 6.23 & 6.45 \\
\hline ASIA & 1.80 & 2.48 & 7.65 & 0.875 & 3.52 & 6.69 \\
\hline \multirow[t]{2}{*}{ EUROPE } & 3.46 & 5.21 & 10.21 & 3.17 & 7.61 & 10.83 \\
\hline & \multicolumn{6}{|c|}{ Panel C. Minimum } \\
\hline AFRICA & -1.44 & -0.018 & -1.22 & -0.519 & -0.440 & -1.15 \\
\hline AMERICAS & -1.18 & -1.94 & -6.36 & -1.50 & -6.92 & -3.94 \\
\hline ASIA & -1.78 & -2.90 & -4.67 & -1.30 & -4.54 & -4.01 \\
\hline EUROPE & -1.90 & -4.29 & -7.63 & -1.73 & -5.79 & -8.99 \\
\hline
\end{tabular}

Notes. The values include average (panel A), maximum (panel B) and minimum (panel C) significant coefficients for each region. 